\title{
Filología y etnohistoria
}

\section{Una breve historia de la "nueva filología" en Norteamérica}

Nuestro campo [la historia colonial de Latinoamérica] parece haber llegado a una fase en la que las tareas más importantes [...] no requieren de una teórica que rehuya el detalle, ni de una investigación meramente centrada en las fuentes, sino de mentes flexibles que puedan visualizar lo general dentro de lo particular.

LOCKHART (1972: 36)

De todos los ricos campos de estudio que se encuentran en la historia de México, a través de los años ninguno ha superado a la etnohistoria colonial en términos de la excelencia de sus aportaciones.

KICZA (1995: 240)

\section{Matthew Restall}

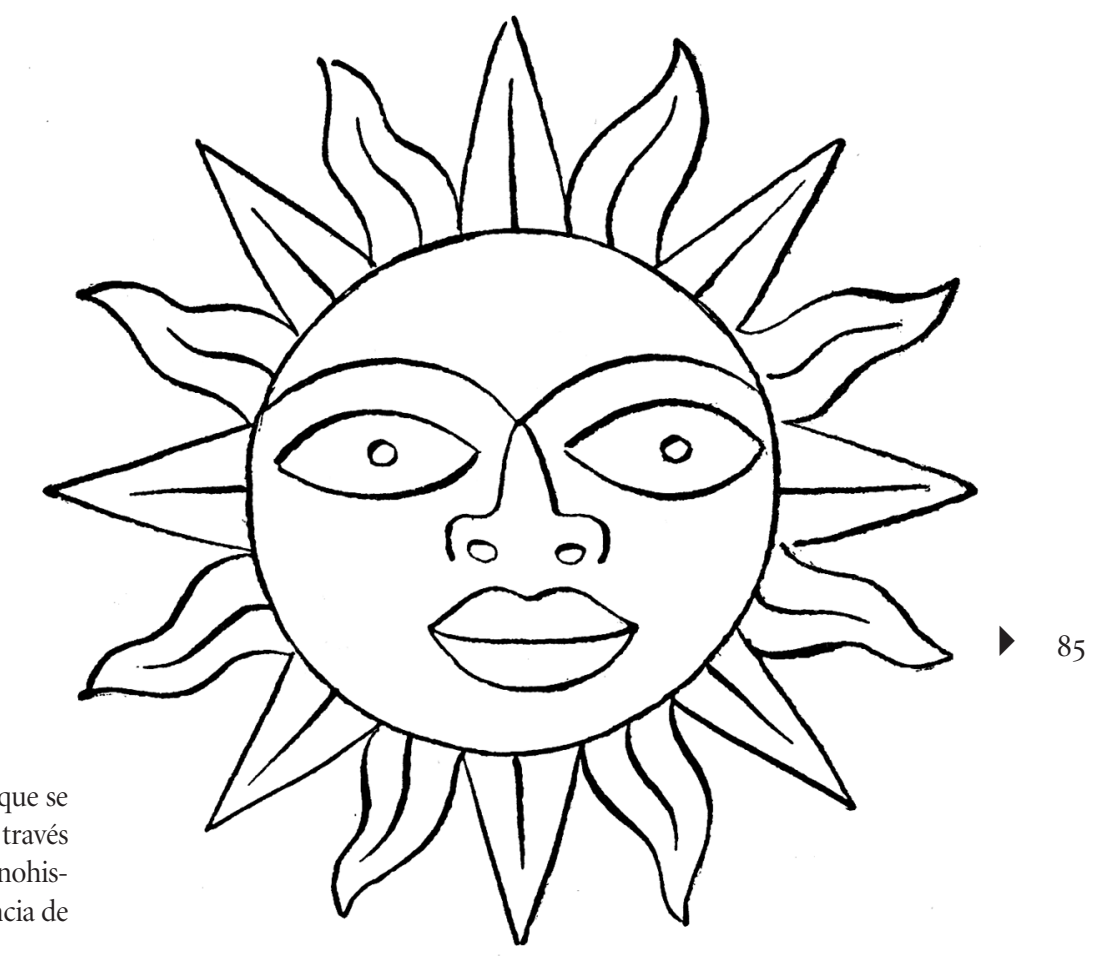

Miguel Covarrubias, 1947

La [nueva filología] ha expuesto el interior de la sociedad indígena colonial de manera fundamental para cualquier análisis cultural, y se ha presentado de manera creíble como la escuela historiográfica del período colonial más innovadora y reconocible como tal hasta el presente.

VAN YOUNG (1999: 234)
S E HA SUGERIDO con frecuencia que hay dos razones que explican la peculiar vitalidad de la etnohistoria de la Mesomérica colonial. Hace unos cuantos años, John Kicza (1995: 240) definió con elocuencia estas dos razones al citar, en primer lugar, la "integridad" y el "vigor" de las civilizaciones indígenas desde tiempos precolombinos hasta el presente y, en segundo lugar, la riqueza y diversidad de las fuentes documentales relevantes al tema. Sin disputar este argumento - de hecho, partiendo de la noción que estos dos factores pueden fungir como supuestos- quisiera sugerir que existe 




un tercer factor que es asimismo pertinente: la concatenación de las actividades de un grupo diverso de investigadores que ha creado una visión colectiva metodológica e interpretativa, y un impulso constructivo que ha permitido la concreción y el desarrollo de dicha visión.

Por supuesto, me refiero a una escuela teórica y metodológica en particular: la escuela que se define de manera creciente como la "nueva filología". El propósito de este artículo es ofrecer una reseña historiográfica de esta escuela: su historia y desarrollo, su localización dentro del contexto de la historia colonial latinoamericana y la etnohistoria de Mesoamérica, sus puntos fuertes y débiles, su trayectoria y significados actuales, y sus prospectos en el futuro. Mi enfoque abarca sólo las publicaciones en lengua inglesa, partiendo del supuesto de que los lectores de Desacatos tendrán una relativa familiaridad con las contribuciones relevantes en lengua española, y con el fin de evitar la repetición de temas discutidos en otros artículos en el presente número.
Ya que este ensayo es una definición in extenso de dicha escuela, quisiera empezar ofreciendo una definición breve de la misma. De manera general, la nueva filología incluye a los investigadores dedicados a la etnohistoria de Mesoamérica durante el período colonial cuyas aportaciones se basan en fuentes primarias en lenguas indígenas, subrayando un análisis filológico de sus fuentes, y enfatizando la importancia crucial de las fuentes nativas para el conocimiento de las sociedades indígenas. Se ha asociado a la nueva filología con los trabajos del historiador James Lockhart, e incluso ha sido llamada la "escuela de Lockhart"; sin embargo, ésta se extiende más allá de Lockhart y de sus discípulos, incluyendo a un número creciente de investigadores en Norteamérica y México - y a un número menor en Guatemala y Europa- que no tienen vínculos directos con este investigador.

Esta escuela tiene sus inicios en el estudio de fuentes en náhuatl, y por lo tanto ha logrado hacer sus contribuciones más detalladas al estudio de la cultura nahua, 
expandiéndose en los últimos años más allá de los estudios nahuas. Sus dos principales contribuciones, no sólo a la etnohistoria colonial de Mesoamérica, sino a la historia colonial de América Latina, han sido el acercamiento a las fuentes primarias indígenas como el centro fundamental de la investigación etnohistórica, y la reorientación de la historia colonial hacia las perspectivas indígenas, combatiendo de esta manera la marginalización de la historia de los pueblos nativos. Superando la producción de otros campos históricos, la nueva filología ha generado un número muy elevado de obras sobre la historia social y cultural de Latinoamérica. Esta escuela se ha desarrollado en la fructífera intersección de la historia y la antropología, encontrando sus raíces y sustento en ambas disciplinas. Sin embargo, en términos de su metodología y de la preparación de sus adherentes, la nueva filología se localiza principalmente en la historia $-\mathrm{y}$ con una incidencia ligeramente menor, en la antropologíacon la participación de la lingüística, la historia del arte, y otras disciplinas. De acuerdo con Lockhart (2000: 367), la nueva filología pertenece a la historia simplemente "porque la historia es la 'disciplina’ más flexible y extensa”.

Quisiera proponer que la historia de la nueva filología consiste de tres fases, y las siguientes tres secciones de mi ensayo ilustrarán cada una de ellas. El fulcro analítico de este ensayo se encuentra en la tercera sección, en la que presentaré argumentos sobre la localización, relevancia, y perspectivas para el futuro de dicha escuela.

\section{PRIMERA FASE (1976-1992)}

La primera fase de la nueva filología norteamericana inició en 1976. Antes de esta fecha $-\mathrm{y}$ retrocediendo un período de más de cien años, casi hasta el punto de desaparición de las fuentes indígenas utilizadas por esta escuela - se había localizado, organizado, traducido, publicado y analizado un número considerable de fuentes primarias coloniales en náhuatl, en algunas lenguas mayances, y en otras lenguas mesoamericanas. Sin embargo, la suma de estos trabajos no había cristalizado en una interpretación coherente de las sociedades mesoamericanas durante el período colonial ni había influenciado

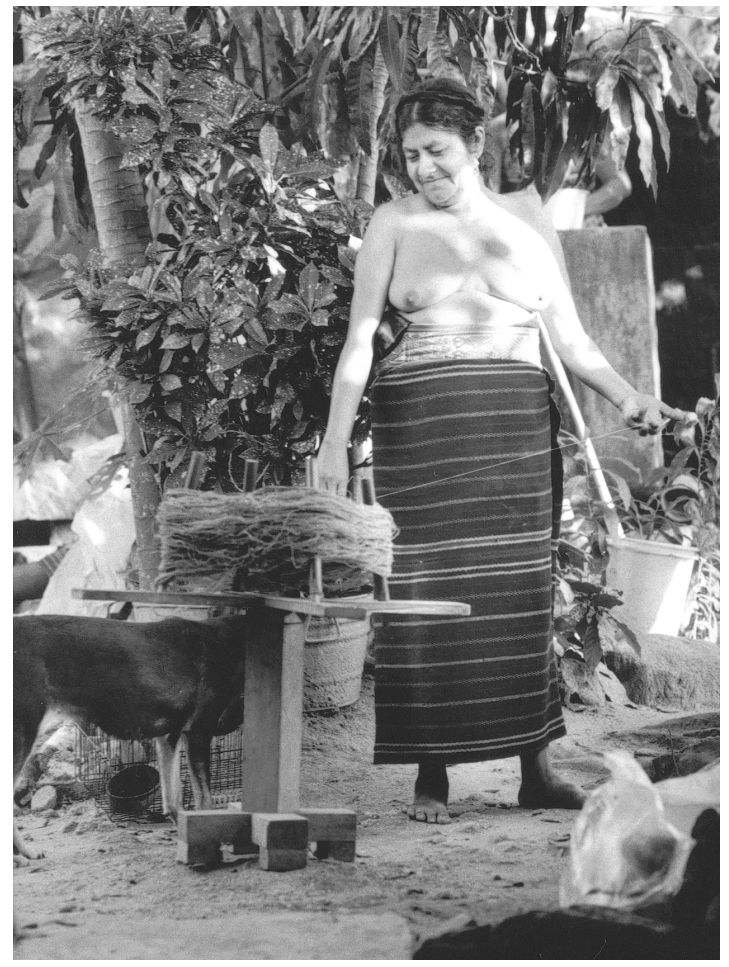

Pinotepa de Don Luis, mixteca de la Costa, Vittorio D’Onofri, 1995

de manera decisiva la historiografía de los pueblos nativos de México o Guatemala. De hecho, en Norteamérica, este tipo de investigaciones se encontraba al margen del statu quo académico; algunos pioneros como Daniel G. Brinton o Ralph Roys tuvieron que operar en parte fuera del ámbito académico, mientras que los trabajos de Miguel León-Portilla, Alfredo López Austin y otros excelentes investigadores mexicanos no alcanzaban su debido reconocimiento en el ámbito académico de habla inglesa por el simple hecho de no estar vinculados con universidades británicas o norteamericanas. Las aportaciones anteriores a 1976 tuvieron gran importancia, pues éstas constituyen las raíces de las cuales brotó la nueva filología, y muchos de estos trabajos siguen siendo relevantes. Sin embargo, en retrospectiva, 1976 puede ser considerado el momento decisivo en la fundación de esta escuela y como el punto de partida de un tipo de etnohistoria cuya visión - y oportuna aparición- motivó el estudio de fuentes indígenas y redefinió los ámbitos 
principales de la etnohistoria en Norteamérica.

Este momento fue marcado por la aparición de dos publicaciones innovadoras de fuentes coloniales en náhuatl. Más allá de los códices [Beyond the Codices], la obra de Arthur Anderson, Frances Berdan y James Lockhart, presentó una selección de fuentes notariales cotidianas traducidas del náhuatl al inglés, así como un análisis extenso ofrecido en un prólogo y en notas al pie de página. Este volumen sugirió que un grupo de documentos aparentemente superficial cuyo estudio había sido descartado - testamentos y registros de tierras escritos por notarios indígenas- podían convertirse en ricas fuentes de datos históricos. En este mismo año, Frances Karttunen y Ja-

mes Lockhart publicaron un trabajo titulado El náhuatl en el período intermedio: Los fenómenos de contacto lingüístico en los textos coloniales $[\mathrm{Na}-$ huatl in the Middle Years: Language Contact Phenomena in Texts of the Colonial Period], el que mostró detalladamente la manera en que el análisis de fuentes nahuas podía revelar patrones y dinámicas de contacto cultural que no habían sido percibidas con anterioridad. (Para un interesante testimonio personal de este proyecto de colaboración, véase Lockhart, 2000: 350-356.) Estos dos volúmenes constituyeron un llamado académico a las armas.

Durante los siguientes quince años, esta llamada encontró un eco en un flujo de disertaciones doctorales y monografías, acompañadas por un número creciente de compilaciones de fuentes indígenas, ponencias, ensayos, y artículos. La mayor parte de estos trabajos fue realizada por los discípulos de James Lockhart en la Universidad de California en Los Ángeles (UCLA), quienes llevaron a cabo una serie de disertaciones basadas en fuentes nahuas de comunidades y regiones específicas del centro de México, entre 1983 y 1989 , que ahora bosquejaré en orden cronológico (aunque se puede consultar Lockhart, 1991b si se desea una visión más detallada). Seguidamente, discutiré las aportaciones de Lockhart y de otros investigadores que intervinieron en esta primera fase de la nueva filología norteamericana.

La primera de estas disertaciones fue concluida por S. L. Cline en 1983, para luego ser publicada en 1986: Culhuacán en el período colonial, 1580-1600: La historia social de un pueblo azteca [Colonial Culhuacan, 1580-1600: A Social History of an Aztec Town]. Esta obra puso en marcha las posibilidad, sugerida por Beyond the Codices, que los testamentos nahuas podrían iluminar la vida social del altepetl. En una maniobra que se ha vuelto distintiva dentro de la nueva filología, en 1984, Cline y León-Portilla publicaron la transcripción y traducción de las fuentes primarias utilizadas en dicha obra; en 1993, Cline publicó asimismo un volumen de fuentes nahuas no utilizadas en su estudio original. En realidad, la inclusión de estas transcripciones y traducciones reflejan fielmente las tendencias de esta escuela.

Las dos siguientes disertaciones de este grupo fueron concluidas en 1984. La obra de Susan Schroeder — publicada en 1991 en inglés como Chimalpahin and the Kingdoms of Chalco y en español en 1994 por El Colegio Mexiquense bajo el título de Chimalpahin y los reinos de Chalco - se distingue de otras disertaciones en esta categoría al enfatizar la historia intelectual de un historiador 
nahua del siglo XVII en lugar de la historia social de su altepetl, si bien la contribución de esta obra reside en su exitoso tratamiento de ambos temas. Siguiendo el patrón de la nueva filología, Schroeder ha iniciado la publicación en seis volúmenes de toda la obra escrita de Chimalpahin, incluyendo algunos manuscritos que fueron recuperados en la década de los ochenta; los primeros dos volúmenes de esta serie aparecen en la presente bibliografía como Anderson y Schroeder, 1997. Por otra parte, Stephanie Wood concluyó su aún inédita disertación en 1984. Este estudio de las comunidades coloniales nahuas en el valle de Toluca ha contribuido a nuestro conocimiento de la integridad corporativa y de la ideología del altepetl colonial. Si bien los estudios de esta primera fase fueron acompañados por algunos trabajos que no se mencionan aquí, debe hacerse notar que Wood ha publicado un número respetable de artículos, como su contribución a la colección titulada Indian Women of Early Mexico [Mujeres indígenas del México colonial temprano], que fue publicada en 1997 por tres antiguos estudiantes de Lockhart (véase Schroeder, Wood y Haskett, 1997).

Las siguientes dos disertaciones supervisadas por Lockhart durante esta primera fase han sido publicadas con revisiones sustanciales que han añadido materiales novedosos, al costo de dejar fuera algunos datos relevantes, por lo que las tesis originales retienen su interés. La obra de Robert Haskett, terminada en 1985 y publicada en 1991 como Indigenous Rulers: An Ethnohistory of Town Government in Colonial Cuernavaca [Señores indígenas: Una etnohistoria del gobierno local en la Cuernavaca colonial] ofrece una nueva perspectiva del gobierno municipal en Cuerna- vaca y de la cultura política del altepetl. Como los etnohistoriadores que he mencionado anteriormente, Haskett no sólo utilizó fuentes inéditas en náhuatl, sino que también descubrió muestras de un género colonial poco conocido: la documentación de elecciones realizadas dentro del altepetl election records —un género posteriormente identificado en el Yucatán colonial. Su trabajo se ha convertido en un punto de referencia necesario para el estudio del gobierno local en Mesoamérica durante el período colonial. Por otra parte, Rebecca Horn realizó una contribución similar a la de Haskett en cuanto al estudio de la tenencia de tierras. Su disertación, terminada en 1989 y publicada en parte en 1997 bajo el título de Postconquest Coyoacan: Nahua-Spanish Relations in Central Mexico, 1519-1650 [Coyoacán después de la conquista: Las relaciones entre nahuas y españoles en el centro de México, 1519-1650] analizó una vasta serie de documentos sobre la tenencia y el traspaso de tierras en Coyoacán, así como otros documentos en náhuatl, que hacen resaltar la dinámica de la vida social, política y económica entre los nahuas de esta región.

En la década de los ochenta, Lockhart publicó una serie de estudios _publicados en la colección de 1991 intitulada Nahuas and Spaniards [Nahuas y españoles] — en respuesta al llamado a las huestes filológicas que había lanzado en 1976. Estos trabajos, aunados a las cinco disertaciones que mencioné anteriormente, fueron adelantos de la magna obra que aparecería en 1992 bajo el título de The Nahuas After the Conquest [Los nahuas después de la conquista]. Esta obra, con la que culmina la primera fase de la "nueva filología", presentó un análisis lúcido y extraordinariamente detallado de todo aspecto
Nacimiento bajo las casas 8 Muerte y 9 Venado; Códice Florentino 
imaginable de la vida del altepetl desde mediados del siglo XVI hasta mediados del XVIII. Este libro ofrece también una perspectiva general de la cultura y sociedad nahuas durante el período colonial. Se podría argüir que los nativos del centro de México habían sido considerados simplemente como "indios" por mucho tiempo. La monografía de Lockhart los hizo aparecer de nuevo como miembros de la cultura nahua.

The Nahuas After the Conquest podría ser vista como el cubo de una rueda cuyos radios y bordes son los trabajos auxiliares publicados por Lockhart entre 1986 y 1998. Dichos trabajos presentan fuentes en náhuatl transcritas y traducidas al inglés, aunque con una introducción y comentarios que les conceden el carácter de monografías, sobre todo si se consideran como partes de The Nahuas After the Conquest. Entre estas publicaciones se deben mencionar The Tlaxcalan Actas (impresa en 1986 y escrita con la ayuda de Berdan y Anderson); The Art of Nahuatl
Speech: The Bancroft Dialogues [El arte del habla náhuatl: Los diálogos de la Biblioteca Bancroft], impresa en 1987, escrita con la ayuda de Karttunen, y notable por ofrecer no una, sino dos traducciones al inglés, una literal y la otra fluida); We People Here: Nahuatl Accounts of the Conquest of Mexico [Nosotros la gente de aquí: Narrativas nahuas sobre la conquista de México], 1993, la que ofreció dichas narrativas en su versión original en náhuatl, su traducción, así como la estructura de los textos originales, en vez de versiones compuestas; finalmente, The Story of Guadalupe [La relación de Guadalupe], escrita con ayuda de Lisa Sousa y Stafford Poole, 1998, un estudio y edición definitiva en náhuatl y en inglés del Huey tlamahuiçoltica, el texto sobre las apariciones guadalupanas publicado en 1649 por Laso de la Vega. Adicionalmente, un volumen de ensayos y artículos similares en contenido a Nahuas and Spaniards fue publicado en el 2000 bajo el título de Of Things of the Indies [Sobre las cosas de Indias], y una

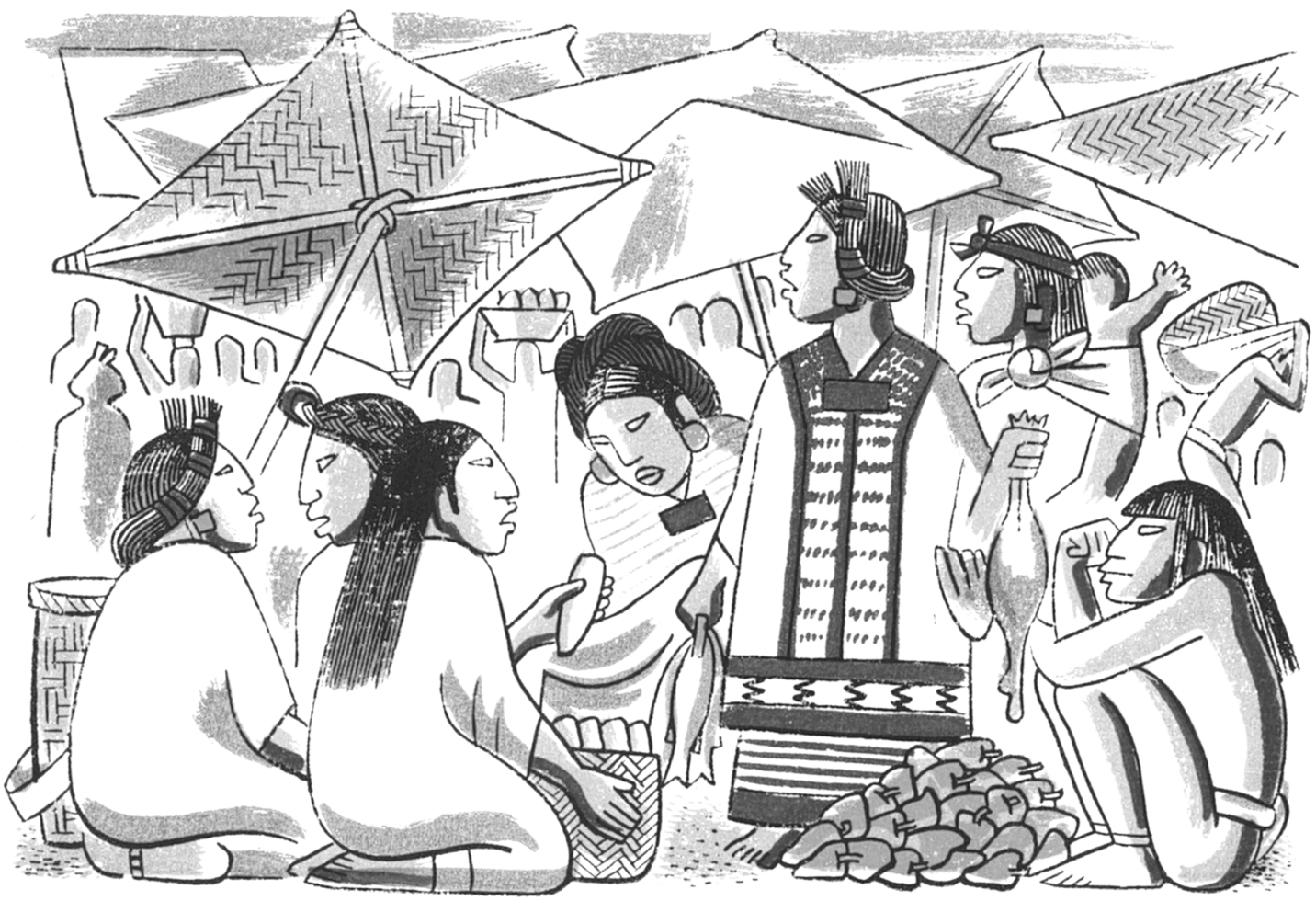

Miguel Covarrubias, 1942 
guía para el aprendizaje del náhuatl escrito aparecerá dentro de los siguientes dos años.

Si bien la primera fase de la nueva filología norteamericana ha sido sustancial y de gran influencia, sus aportaciones no se deben atribuir sólo a Lockhart y a sus estudiantes. Otros especialistas realizaron contribuciones esenciales durante este período (1976-1992); aunque estos trabajos puedan ser relacionados con otras escuelas historiográficas, no dejan de ser parte de lo que persisto en calificar como "nueva filología". Quisiera destacar el trabajo de tres de estos especialistas. La primera es Frances Karttunen, una lingüista e historiadora que ha colaborado con Lockhart de manera periódica (en la publicación de Nahuatl in the Middle Years [El náhuatl a mediados del período colonial], por ejemplo), pero que ha realizado por su parte tres estudios lingüísticos y etnohistóricos de gran repercusión: un artículo de 1982 sobre la alfabetización entre los nahuas coloniales, el Analytical Dictionary of Nahuatl [Diccionario analítico del náhuatl], 1983, publicado como complemento a un curso básico sobre la gramática náhuatl realizado con la ayuda de R. Joe Campbell, y Nahuatl and Maya in Contact with Spanish [Los contactos de las lenguas náhuatl y maya con la española], 1985, cuyo papel en la segunda fase de la nueva filología se discutirá posteriormente.

La segunda es la antropóloga Louise Burkhart, quien ha contribuido a la transformación del estudio de la religión en México durante el siglo XVI, uniendo su reexaminación de la "conquista espiritual" a los objetivos de la nueva filología. Su disertación doctoral fue editada y publicada en 1989 como The Slippery Earth: Nahua-Christian Moral Dialogue in Sixteenth-Century Mexico [ $\mathrm{La}$ tierra resbaladiza: El diálogo moral nahua-cristiano en el México del siglo XVI], a la cual podemos añadir la transcripción y traducción de la obra de teatro de evangelización en náhuatl más temprana hasta ahora conocida, Holy Wednesday: A Nahua Drama from Early Colonial Mexico, así como una docena de estudios varios que van desde artículos especializados (Burkhart, 1995) hasta ensayos en libros de texto (Burkhart, 1996b).

La tercera especialista es Susan Kellogg, una antropóloga cuyo trabajo ha contribuido al forjamiento de vínculos entre la nueva filología, la historia y la antropología. Si

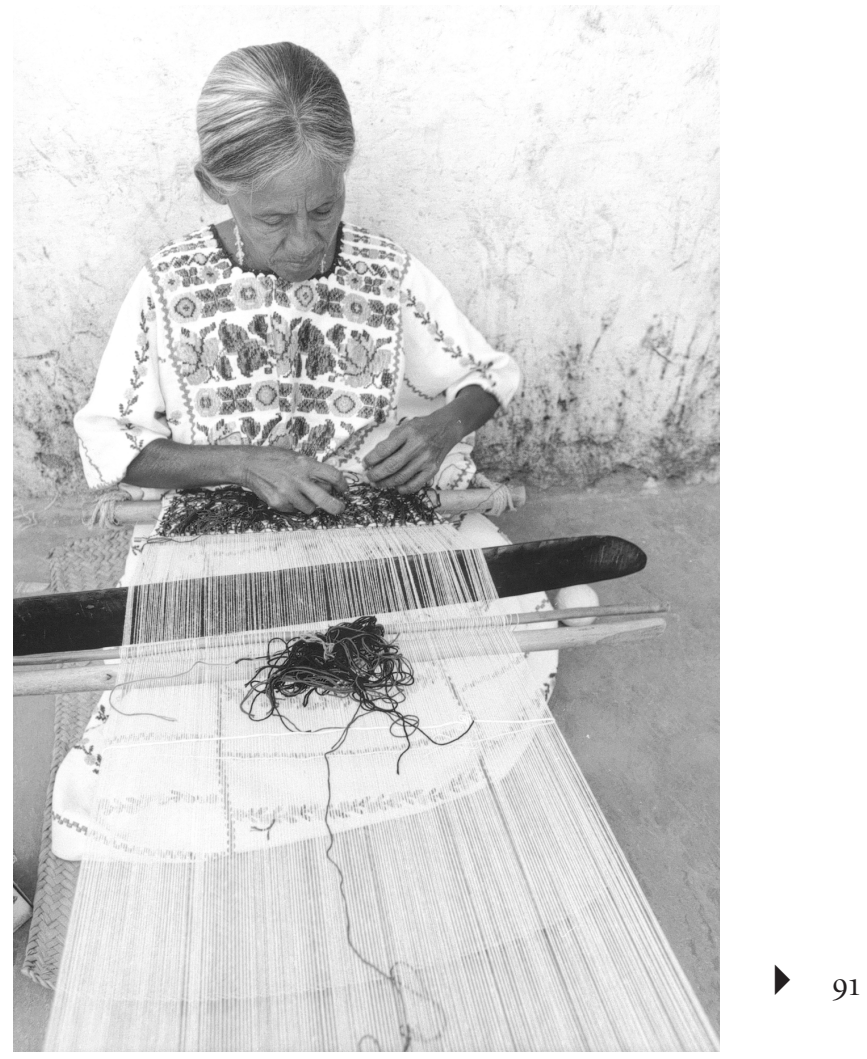

San Pedro Amuzgo, amuzga, Vittorio D’Onofri, 1995

bien su monografía - titulada Law and the Transformation of Aztec Culture [El derecho y la transformación de la cultura azteca] no apareció hasta 1995, Kellogg generó varios análisis de fuentes nahuas del valle de México en los ochenta y noventa, y debe ser considerada parte de la primera fase del desarrollo de la nueva filología. Como parte de esta escuela - y sin haber cursado su doctorado con Lockhart-, Kellogg ha usado fuentes judiciales y realizado un estudio social del derecho colonial que sigue la trayectoria de Woodrow Borah más que cualquier otro etnohistoriador. Por otra parte, su contribución ha sido de gran importancia por haber utilizado fuentes nahuas para promover una hipótesis que es en cierto modo antitética a las propuestas de Lockhart. Mientras que Lockhart (1992: 433-434) caracteriza a los siglos XVI y XVII como a una edad dorada en el desarrollo cultural indígena, Kellogg percibe un deterioro en la autonomía 
cultural nahua dentro del cual los tribunales funcionan como "un instrumento de conversión cultural y de consolidación de la hegemonía cultural española” (Kellogg, 1995: 214).

$\mathrm{Al}$ interpretar los cambios en las fuentes manuscritas indígenas como parte de un proceso de pérdida cultural, y no como prueba de un renacimiento indígena, Kellogg nos muestra que Borah no es su única influencia historiográfica. En realidad, el trabajo de Kellogg parece haber sido influenciado por una serie de historiadores de nacionalidad francesa (Tzvetan Todorov, Christian Duverger y Serge Gruzinski, entre otros) o educados en París (como Enrique Florescano y Walter Mignolo) cuyos trabajos han sido traducidos al español y al inglés. Si bien The Conquest of America, de Todorov, y Man-Gods in the Mexican Highlands, de Gruzinski, son las publicaciones en inglés más conocidas de este grupo, el trabajo más relevante en esta discusión, dado su análisis de fuentes en lenguas indígenas, es The Conquest of Mexico, de Gruzinski (la edición inglesa de 1993 de La colonisation de l'imaginaire, 1988). De cualquier manera, este trabajo no está directamente afiliado con la nueva filología porque utiliza el lenguaje de la historia cultural sobre "la colonización de lo imaginario" para presentar visiones tradicionales del deterioro cultural indígena. Gruzinski y otros han puesto al día el paradigma de la interacción entre nahuas y españoles delineado por Robert Ricard (y que Lockhart [1992: 2-3] ha llamado el "modelo del reemplazo"). En otras palabras, estos trabajos presentan lo que Eric Van Young (1999: 235) ha llamado "una forma más tradicional de la historia intelectual". La diferencia entre Gruzinski y Kellogg es que el trabajo de la segunda simultáneamente captura el espíritu de la nueva filología y cuestiona uno de sus postulados principales (que las fuentes en lenguas indígenas

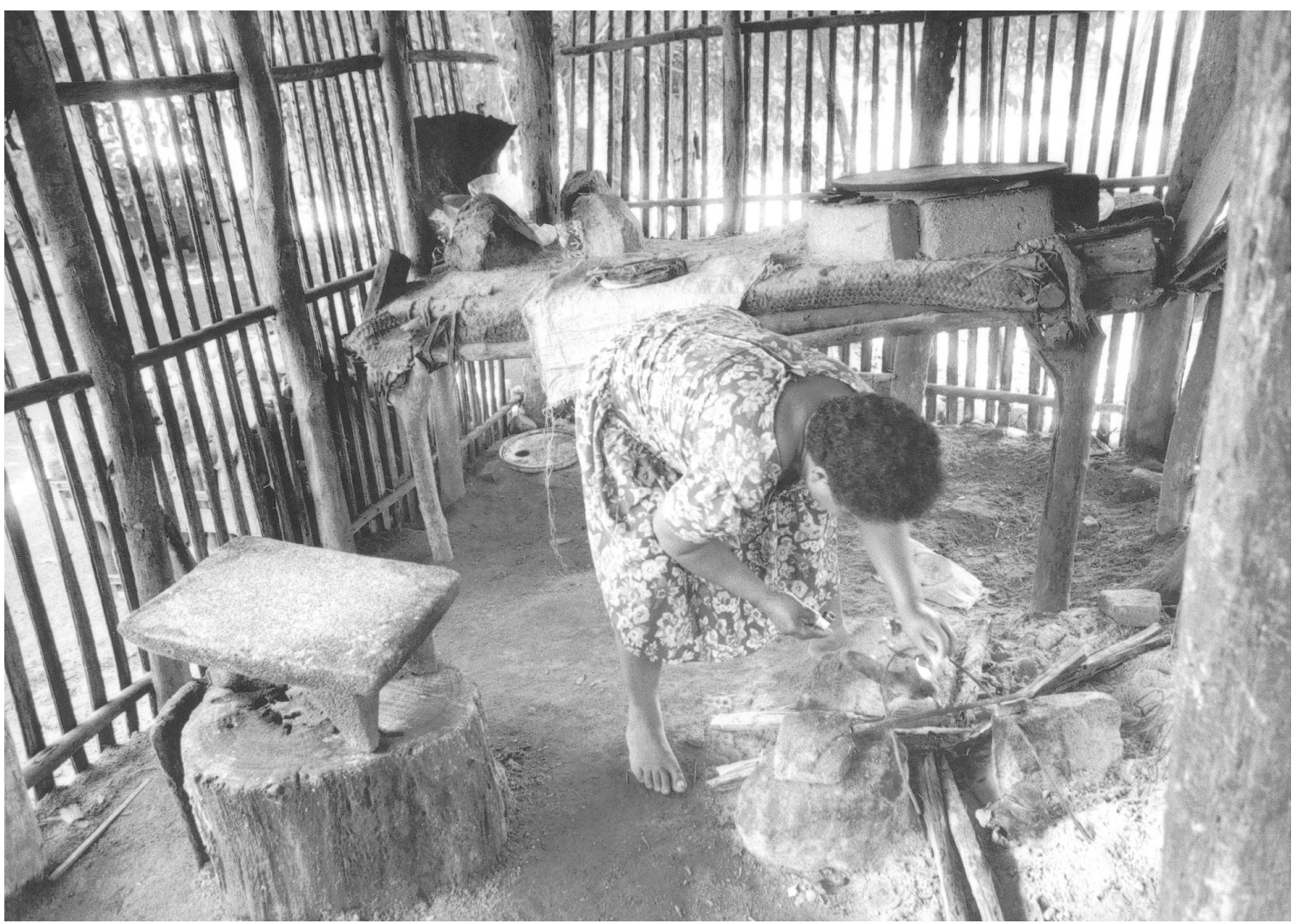

San Lorenzo Teitipac, zapoteca del Valle, Vittorio D’Onofri, 1995 
son pruebas de vitalidad cultural), mientras que el primero, al asumir la existencia de un declive cultural, cuestiona la mismísima raison d'être de la nueva filología.

Antes de delinear la segunda fase de la nueva filología, se debe mencionar los trabajos de algunos filólogos de la primera fase. En 1955, Anderson inició, junto con Charles Dibble, un proyecto de traducción del Códice florentino de Sahagún; la obra resultante fue un punto de referencia absoluto para las raíces de la nueva filología y para su primera fase, durante la cual finalizó dicho proyecto. Existe también el trabajo de varios lingüistas y etnohistoriadores que hicieron contribuciones a esta escuela durante su primera fase - entre ellos se debe mencionar a la edición conjunta de J. Richard Andrews y Ross Hassig del Tratado de las supersticiones y costumbres gentílicas que oy biven entre los indios naturales desta Nueva España, de Hernando Ruiz de Alarcón, y a las obras de William Bright, Una Canger, R. Joe Campbell y Mary Clayton. En esta categoría encontramos a John Bierhorst, cuyas traducciones de textos nahuas $(1985 ; 1992)$ se distinguen en parte por ser una contribución a la nueva filología en un sentido completamente opuesto al de Lockhart (como lo afirma el mismo Lockhart (1991a: 141-157). Finalmente, se debe mencionar el trabajo de Pedro Carrasco y J. Jorge Klor de Alva, dos etnohistoriadores y antropólogos que han publicado un número considerable de artículos en español y en inglés sobre fuentes nahuas.

\section{SEGUNDA FASE (1992-2000)}

En 1992, la segunda fase de la nueva filología emerge a través de la expansión geográfica de sus principios y métodos al sur del área cultural mesoamericana. Esta fase podría ser dividida entre las actividades de los estudiantes de Lockhart y la de otros filólogos. Entre 1992 y 1998, cuatro estudiantes finalizaron sus disertaciones doctorales bajo la supervisión de Lockhart. Kevin Terraciano ha utilizado fuentes prehispánicas y coloniales de la cultura mixteca (o ñudzahui), tanto pictográficas como alfabéticas, para modificar nuestras percepciones de las comunidades indígenas en Oaxaca. Su disertación doctoral de 1994 —titulada Nudzahui History: Mixtec Writing and
Culture in Colonial Oaxaca [La historia ñudzahui: La cultura y escritura mixteca en el Oaxaca colonial] acaba de ser publicada como monografía por Stanford University Press (para un resumen, véase su artículo del 2000 en la bibliografía). La disertación inédita de Lisa Sousa - Women in Native Societies and Cultures of Colonial Mexico [Las mujeres en las sociedades y culturas indígenas del México colonial] emplea fuentes en náhuatl y mixteco para examinar el rol y status social de las mujeres indígenas en esferas domésticas y comunitarias en el centro de la Nueva España durante los primeros dos siglos del período colonial (véase también su artículo en Schroeder, Wood y Haskett, 1997). ${ }^{1}$

Podría decirse que la etnohistoriografía colonial en Yucatán se asemeja a la del centro de México por dos razones distintas. En primer lugar, ya existían monografías detalladas sobre las comunidades indígenas antes del arribo de la nueva filología — la obra maestra de Charles Gibson sobre los nahuas, The Aztecs under Spanish Rule: A History of the Indians of the Valley of Mexico, 1519-1810 [Los aztecas bajo el dominio español: Una historia de los indígenas del valle de México, 1519-1810, 1964], y el estudio de Nancy Farriss sobre los pueblos yucatecos titulado Maya Society Under Colonial Rule [La sociedad maya bajo el dominio colonial, 1984]. Ambos trabajos se basaron en el estudio de fuentes en castellano, lo que permitió la producción de estudios complementarios de fuentes nahuas y yucatecas por parte de los nuevos filólogos que entraron en un debate muy productivo con estas monografías. En segundo lugar, así como los nuevos filólogos encontraron un grupo muy numeroso de fuentes coloniales nahuas en archivos mexicanos, españoles y norteamericanos, varios investigadores han descubierto miles de documentos coloniales en maya yucateco en México, Yucatán, España, Estados Unidos y aun en Gran Bretaña.

En mi propia disertación, que defendí bajo la supervisión de James Lockhart en 1992, hice el intento de llevar

\footnotetext{
${ }^{1}$ Por otra parte, Pete Sigal investigó fuentes en maya yucateco para producir un estudio original de la sexualidad dentro de la cultura maya colonial en su disertación de 1995, Maya Passions: Colonial Yucatecan Ideas of Gender, Sexuality, and the Body [Pasiones mayas: Ideas de los yucatecos coloniales sobre el género, la sexualidad, y el cuerpo humano], la cual fue publicada recientemente por la University of Texas Press.
} 
la nueva filología al terreno yucateco, siguiendo los pasos de una generación de estudiosos de fuentes coloniales mayas como Alfredo Barrera Vásquez y Ralph Roys. En la edición monográfica de mi disertación - publicada en 1997 bajo el título de The Maya World: Yucatec Culture and Society, 1550-1850 [El mundo maya: Cultura y sociedad en Yucatán, 15501850] — propuse que la organización comunitaria maya a nivel municipal, llamada cah en yucateco, era una entidad compleja en la que incidían todos los aspectos de la vida social yucateca en el período colonial. ${ }^{2}$ Es-

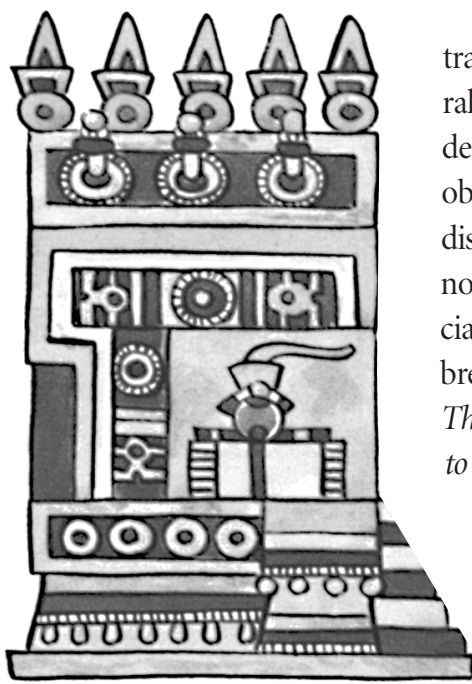

Códice Selden ta visión, que mantiene ciertos paralelos con la interpretación del altepetl por parte de los nuevos filólogos, constituye un intento de contribuir no sólo a los estudios mayas, sino a un entendimiento más profundo de las civilizaciones mesoamericanas. ${ }^{3}$

En 1998 salió a la luz mi trabajo Maya Conquistador [Conquistador maya], un estudio y traducción de fuentes en maya sobre la conquista. Las raíces intelectuales de este libro son cuatro trabajos de particular relevancia a nuestro tema. El primero es Visión de los vencidos, la conocida colección de fuentes nahuas sobre la conquista editada por León Portilla que apareció posteriormente en inglés bajo el título de The Broken Spears [Las lanzas rotas]. El segundo es We People Here [Nosotros la gente de aquí], la versión al inglés de James Lockhart de las fuentes nahuas presentadas en Visión de los vencidos; cabe señalar que el énfasis de Lockhart en la diversidad de las perspectivas nahuas influyó en mi trabajo de manera particular. El tercero es la edición de 1985 del Popol Vuh preparada por Dennis Tedlock, la que demostró que los textos en lengua indígenas podían ser publicadas como

\footnotetext{
${ }^{2}$ Una selección de los documentos yucatecos que utilizé en mi disertación fue publicada bajo el título de Life and Death in a Maya Community [La vida y la muerte en una comunidad maya] en 1995.

${ }^{3}$ De hecho, tal visión fue articulada en una colaboración con Terraciano que apareció inicialmente en Sousa, 1992, para luego ser publicada como Restall, $1997 \mathrm{~b}$.
}

traducciones accesibles al público en general, aun sin la inclusión de transcripciones de las fuentes, sin por ello contribuir a los objetivos de la nueva filología a través de discusiones detalladas de la traducción en notas de pie de página. La cuarta influencia es el análisis de perspectivas mayas sobre la historia colonial y neocolonial en The Indian Christ, the Indian King [El Cristo indígena, el rey indígena, 1981] de Victoria Bricker. Este trabajo enlaza a la nueva filología con la Universidad de Tulane, pues debe reconocerse que, si bien la nueva filología tiene como uno de sus principales centros académicos las actividades de James Lockhart y sus doctorantes en el departamento de historia de la Universidad de California en Los Ángeles, el departamento de antropología de la Universidad de Tulane en Nueva Orleans juega también un papel central en la segunda fase de esta escuela etnohistórica.

Si bien Tulane ha producido análisis de fuentes nahuas (véase Maxwell y Hanson, 1993), la contribución más importante de esta institución a la segunda fase de la nueva filología se ha concentrado en el estudio de comunidades mayas en Yucatán y Guatemala. En 1982 y 1986, Munro Edmonson publicó traducciones de dos de los Chilam Balam yucatecos. Además de su trabajo ya citado, Bricker ha publicado diversos estudios sobre la lengua y la etnohistoria mayas (véase Edmonson y Bricker, 1985, por ejemplo), y supervisó una tesis doctoral que anticipa la segunda fase de la nueva filología — Tekanto in the Eighteenth Century [Tekanto durante el siglo XVIII] de Philip Thompson, publicada recientemente. Otro doctorante de Tulane, John Chuchiak, acaba de concluir un estudio de la extirpación de idolatrías en Yucatán que incluye un análisis de fuentes en yucateco. Finalmente, debe reconocerse el trabajo pionero de Robert Hill sobre la etnohistoria de los mayas cakchiqueles, que aparece en su libro Colonial Cakchiquels [Cakchiqueles coloniales, 1992] y en otras publicaciones. No hay duda de que Bricker, Hill, Maxwell y otros etnohistoriadores de Tulane continuarán con sus aportaciones a la nueva filología en la década que inicia. 


\section{TERCERA FASE (1992-...)}

La primera fase (1976-1992) se concentró en el estudio de fuentes nahuas, y produjo estudios detallados de la vida doméstica, las relaciones de género, la cultura política y la tenencia de la tierra de los nahuas coloniales basados en fuentes nahuas, al tiempo que emergían las ideas fundamentales y los métodos de la nueva filología. En su segunda fase (1992-2000), esta escuela extiende su enfoque de los pueblos nahuas a otros pueblos mesoamericanos coloniales. Ambas fases han contribuido al emplazamiento central de las sociedades indígenas para el análisis de la historia colonial de la Nueva España y de otras regiones de América Latina. El diálogo de la nueva filología con otras disciplinas y campos académicos y su asimilación dentro de los estudios coloniales en Mesoamérica a tal punto que pierde sus características distintivas podrían ser designados como una tercera fase. En otras palabras, como muchas otras escuelas e ismos anteriores, la nueva filología podría ser asimilada hasta el punto de no ser reconocida como una escuela particular.

No se pueden dar fechas precisas para esta tercera fase, pero ésta se manifiesta en algunos estudios que aparecen en la década de los noventa. Por lo tanto, se podría proponer que esta fase inicia alrededor de 1992, de manera paralela a la segunda, pero con un curso distinto a la misma. La diversa naturaleza de esta fase la vuelve difícil de delinear. Para los propósitos de este trabajo, presentaré esta fase en el contexto de tres modos de interacción entre la nueva filología y otros campos académicos. Esta presentación se vuelve entonces tanto un resumen de los trabajos existentes como una serie de sugerencias sobre posibles contribuciones para el futuro.

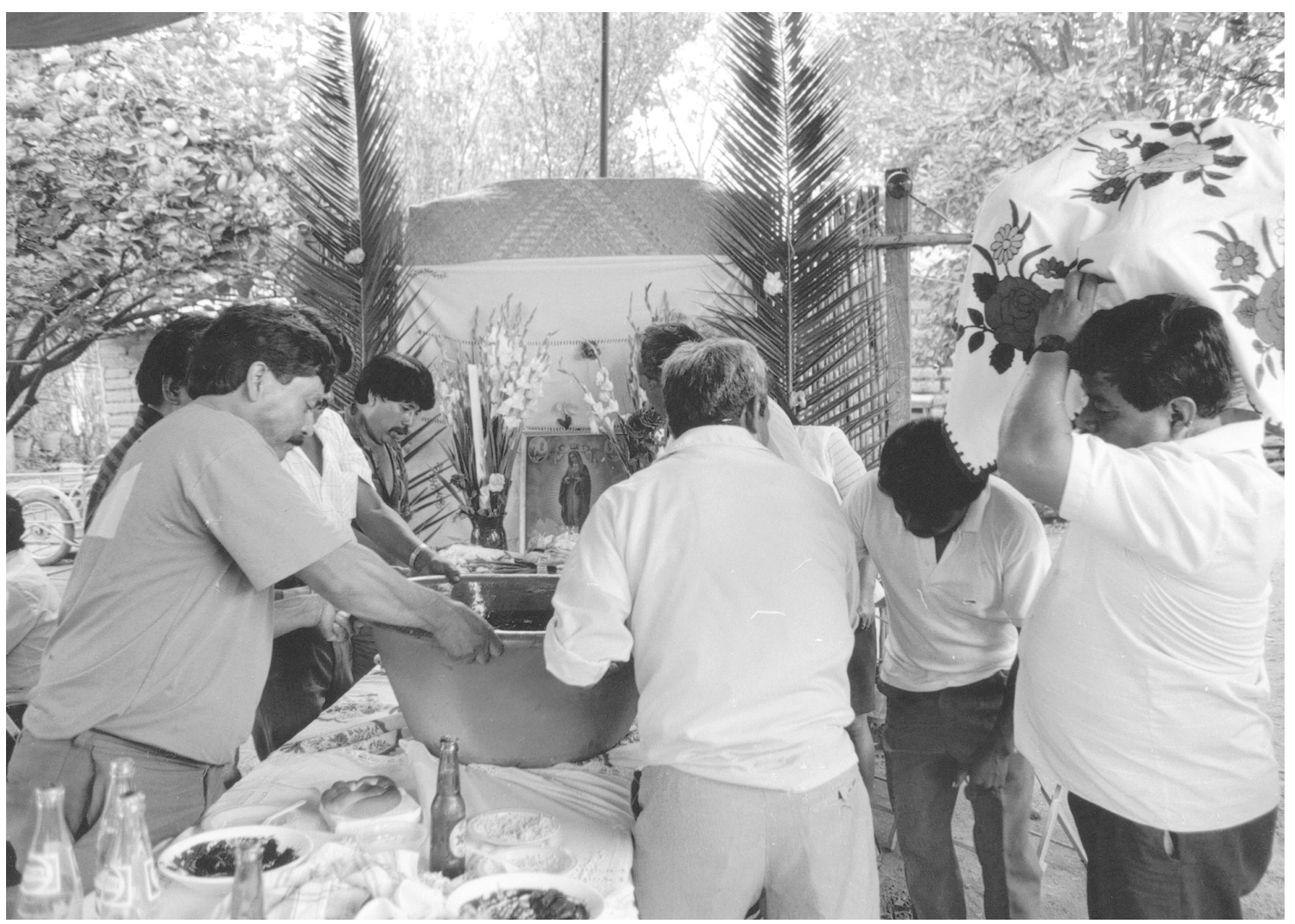

San Juan Teitipac, zapoteca del Valle, 1995 


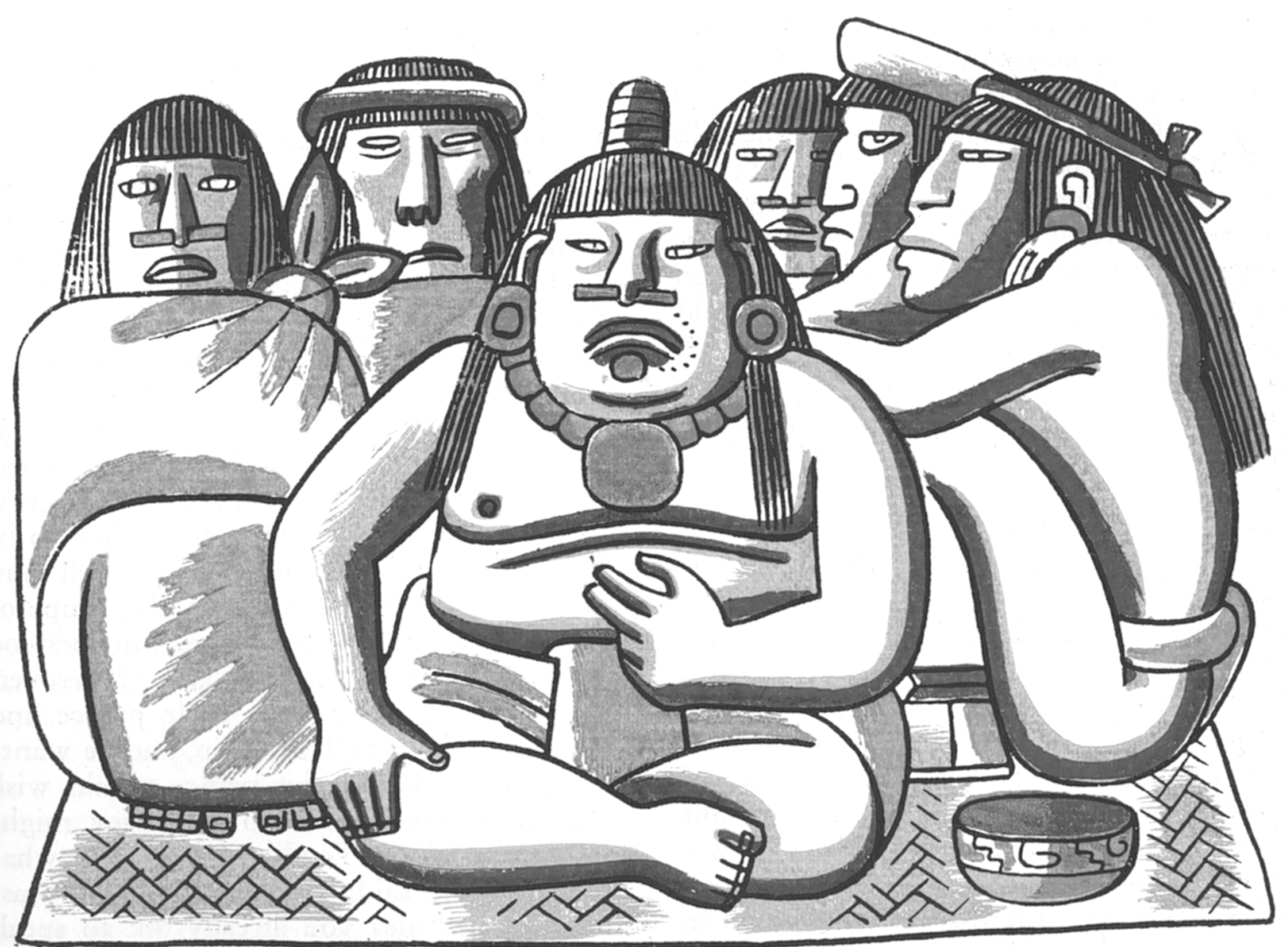

Miguel Covarrubias, 1942

El primer modo de interacción se refiere a disciplinas fuera del campo de la historia y la etnohistoria antropológica. Desde sus orígenes, la nueva filología fue interdisciplinaria, pero este aspecto se ha desarrollado de manera considerable en los últimos años, particularmente en lo concerniente a la antropología lingüística. La colaboración inicial de Lockhart y Karttunen constituyó una convergencia de métodos históricos (favorecidos en Lockhart, 1992) y lingüísticos (presentados en Karttunen, 1983). Como Bricker, Karttunen anticipó el movimiento hacia la etnohistoria maya con su trabajo Nahuatl and Maya in Contact with Spanish. Además de esta poco conocida contribución, el análisis de documentos yucatecos coloniales realizado por William Hanks — publicado en una serie de artículos bien conocidos (Hanks, 1986, 1987) y en Language and Communicative Practices [El lenguaje y las prácticas de comunicación, 1996] — han demostrado las só- lidas contribuciones que los métodos de la antropología lingüística pueden hacer dentro del campo de la etnohistoria colonial. La doble convergencia en el período colonial maya, tanto por parte de arqueólogos y epigrafistas que pasan del posclásico a la colonia ( $v$.g., Bricker y Hill) como por parte de etnólogos que retroceden del presente al pasado colonial (v.g., Hanks) sugiere que la antropología lingüística seguirá jugando un papel importante en el desarrollo de la nueva filología en el sureste de Mesoamérica.

Debe asimismo mencionarse el papel interdisciplinario de la historia del arte. Los elementos visuales de los textos mesoamericanos coloniales - pinturas murales, ilustraciones en códices pictográficos o alfabéticos y mapas - han cautivado la atención de muchos historiadores del arte. Aunque este interés se ha dirigido principalmente al Posclásico y tal orientación persiste, el interés de historiadores del arte por el estudio de textos del siglo 
XVI por su relevancia al período colonial va aumentando. Tres trabajos relevantes en este sentido son la disertación de Jeanette Peterson, publicada en 1993 bajo el título de The Paradise Garden Murals of Malinalco [Los murales del jardin paradisiaco en Malinalco], The Mapping of New Spain [Cartografía de la Nueva España, 1996] de Barbara Mundy, y la disertación inédita de Constance Cortez sobre el árbol genealógico de la familia Xiu en el Yucatán del siglo XVI. Aunque estos trabajos examinan imágenes y no textos en lenguas mesoamericanas, el énfasis que dan a la interpretación de imágenes para el análisis de la Mesoamérica colonial exhibe ciertas correspondencias con la nueva filología. Por otra parte, la tesis doctoral inédita de Dana Leibsohn de 1993 en torno a la Historia toltecachichimeca muestra que los métodos convencionales de la nueva filología - la traducción y análisis de documentos nahuas- puede combinarse con la metodología de la historia del arte de una manera muy productiva.

Un tercer modo de interacción concierne la relación entre fuentes en lenguas indígenas y fuentes en español, así como la relación entre la etnohistoria y la historia social. Cabe aquí destacar varios puntos. En primer lugar, el estudio de las fuentes en lenguas indígenas no hace disminuir la importancia de las fuentes españolas. Aunque algunos críticos de la nueva filología han acusado a sus practicantes de negar la importancia de las fuentes en castellano, la mayor parte de los miembros de esta escuela no han llegado a tal conclusión. Si bien los adherentes a los llamados "estudios subalternos" han sugerido que dicha corriente es una alternativa preferible a otras metodologías históricas para la América Latina —véase Mallon, 1994; y Latin American Subaltern Studies Group, 1995- la nueva filología se ha presentado solamente como una fase en el desarrollo de las disciplinas históricas: si bien las fuentes en lenguas indígenas ofrecen perspectivas únicas, el objetivo a largo plazo es incorporar estas fuentes a otras existentes en lenguas europeas para ampliar nuestra comprensión de las sociedades indígenas coloniales. Este objetivo se manifiesta en las monografias ya citadas de Horn (1997) y Terraciano (2001), así como en un artículo reciente sobre las cofradías nahuas de la ciudad de México de Susan Schroeder (2000), que combina el estudio de fuentes nahuas y
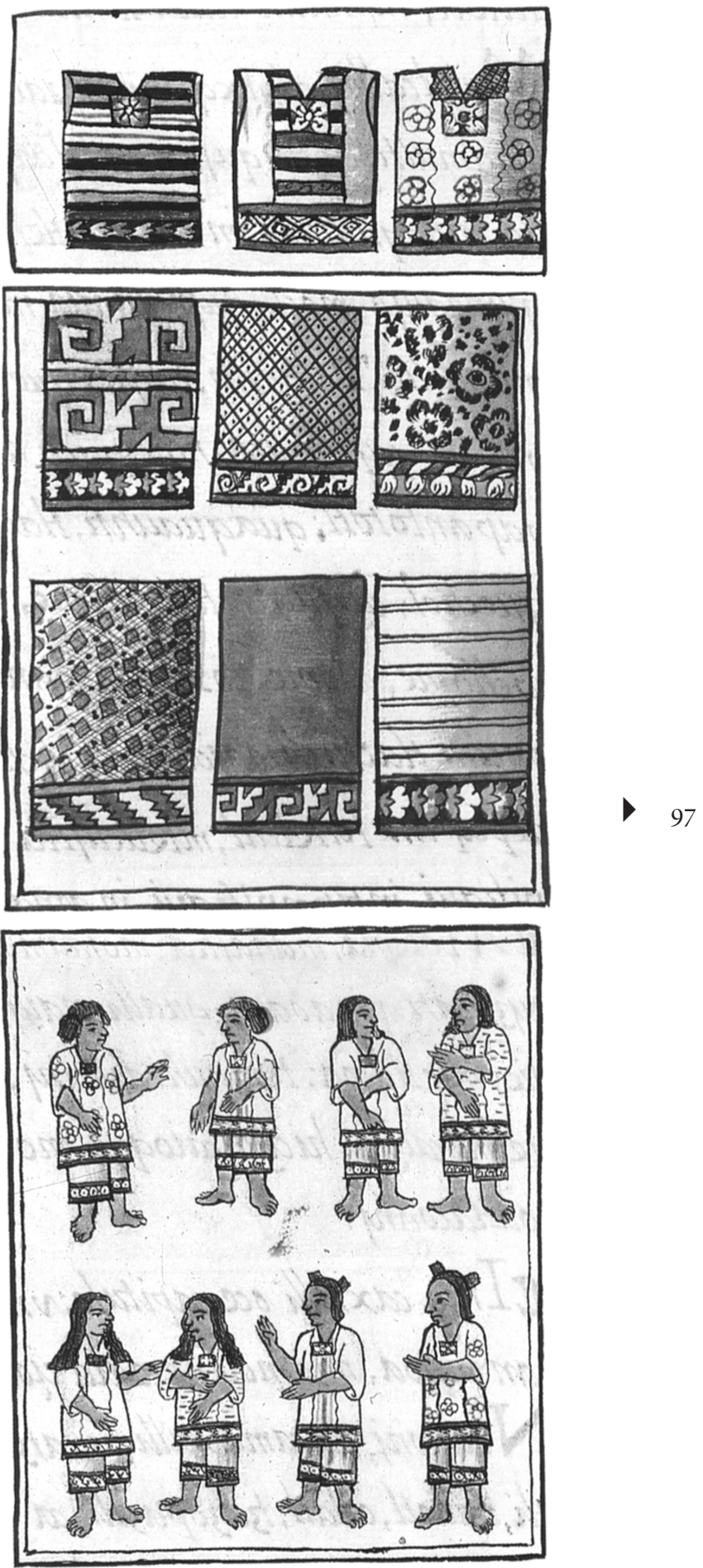

Vestidos y estilos de peinado de mujeres nobles; Códice Florentino 
españolas. Por supuesto, estos ejemplos son sólo una muestra mínima del trabajo reciente de los etnohistoriadores norteamericanos.

No existe una buena razon para restringir la metodología lingüística de la nueva filología al estudio exclusivo de fuentes en lenguas indígenas. El análisis detallado del lenguage y de su uso —así como el énfasis en contribuciones empíricas por encima de las contribuciones teóricas - que ha caracterizado a esta escuela puede ser aplicado a fuentes españolas. El principio neofilológico de demandar, además de una buena navegación por los diccionarios coloniales, una pericia gramatical y léxica en el idioma mesoamericano bajo análisis se puede aplicar también a la lengua española. Hay que destacar que estos principios podrían diferir de la abundante explicación de textos realizada en el campo de los estudios literarios dada una preferencia por la argumentación teórica dentro de la crítica literaria, y las suspicacias posmodernas en cuanto a los textos en sí.

De cualquier manera, dado el papel central que tienen las fuentes en lenguas mesoamericanas dentro de la nueva filología, se podría argumentar que extender los métodos de esta escuela a otras lenguas es una proposición contradictoria. Hay que recordar, por supuesto, que la mayor parte de las sociedades indígenas en las colonias españolas de América no produjeron textos en sus lenguas maternas, o nos heredaron un número muy reducido de tales textos. Los estudiosos de la historia colonial andina han respondido a la ausencia de tales fuentes a través de una gama de metodologías más y más sofisticadas, y no hay duda de que los mesoamericanistas pueden aprender lecciones valiosas a través de la experiencia andina. Sin embargo, sigue existiendo una cierta distancia entre mesoamericanistas y andinistas, y aun ciertos proyectos que han intentado explorar un espacio común a ambos campos - tal como Dead Giveaways [Siguiendo las pistas de los difuntos, Kellogg y Restall, 1998]_ tienden a enfatizar tanto diferencias metodológicas y de planteamiento como puntos en común. Algunos de los trabajos sobre textos quechuas (tales como Mannheim, 1991; o Salomon y Urioste, 1991) siguen un planteamiento comparable al de la nueva filología, aunque no forman parte de un movimiento más amplio comparable a esta escuela. Sin embargo, existe la promesa de un diálogo más fructífero entre mesoamericanistas y andinistas.

Por otra parte, debe esperarse un fortalecimiento de la relación entre la teoría y la nueva filología durante la tercera fase de esta corriente. Anteriormente he citado algunos ejemplos de trabajos de esta escuela que han intentado construir vínculos con modelos teóricos ajenos. La cuestión es que tales intentos de cruzar barreras teóricas o metodológicas no puede dejar de beneficiar a la nueva filología, y el interés que la nueva historia cultural ha despertado en círculos académicos norteamericanos puede llevar a un nuevo diálogo entre una y otra escuela. De cualquier manera, no ha perdido validez el comentario hecho por Karen Spalding hace treinta años: "la constante interacción entre la atención cuidadosa a la riqueza de detalles en nuestras fuentes y las hipótesis y modelos cada vez más refinados que tales detalles han enriquecido promete aumentar de manera considerable nuestra comprensión del pasado" (Spalding, 1972: 67).

Quisiera considerar la cuestión de la relación entre la nueva filología y la corriente historiográfica contemporánea que podría denominarse como la nueva historia cultural. ${ }^{4}$ Desde mi perspectiva, una de las ventajas de la nueva filología ha sido la ausencia relativa de "extensos prolegómenos metodológicos y teóricos" y el "ensimismamiento" (Van Young, 1999: 215) que caracteriza a la nueva historia cultural. Si bien la nueva filología es aún relativamente novedosa y es ciertamente historia cultural, se distingue de la nueva historia cultural por su énfasis en datos empíricos y en la importancia de fuentes indígenas, y por su renuencia a aplicar paradigmas provenientes de contextos históricos o culturales muy distintos a los de la Mesoamérica colonial, o a plegarse a los dictados de autoridades en otros campos.

Por otra parte, es común asociar a la nueva filología con la nueva historia cultural. Esto se debe a la tradicional

\footnotetext{
${ }^{4}$ No me refiero aquí a una "Nueva Historia Cultural" [New Cultural History] con mayúsculas. Como respuesta a Claudio Lomnitz (1999: 367), se puede afirmar que no existe tal escuela en la historiografía latinoamericana, pero puede hablarse de planteamientos generales en torno a la historia cultural que aparece en una gama muy variada de trabajos.
} 




San Lucas Ixcotepec, chontal, Vittorio D’Onofri, 1996

división de la historia latinoamericana en dos campos. Aunque cada historiador puede tener una noción distinta de esta separación —y si bien la nueva filología no es la única escuela que concibe la historia social como una unión de elementos económicos y políticos - la historia social o cultural tiende a ser vista en oposición a la historia económica o política. Una de las versiones más recientes de esta división fue articulada en una colección de ensayos publicados en la Hispanic American Historical Review en mayo de 1999 en los que Eric Van Young (1999: 234) arguyó que la nueva filología (bajo otra denominación) formaba parte de la "nueva historia cultural" del período colonial, mientras que la mayor parte de los ensayos restantes no examinaron el período colonial, u omitieron mención alguna a la nueva filología (aunque Susan Socolow [1999: 357] hace una mención breve de Lockhart).

Al leer la descripción que Haber hace de la historia como ciencia social y su crítica de la nueva historia cultural, es difícil asociar a la nueva filología con lo que Haber (1999: 310) llama "análisis formal y cuantitativo". Sin embargo, quisiera sugerir que la nueva filología contiene (de hecho o en potencia) los mejores aspectos de tres posibilidades historiográficas, de acuerdo con las categorías propuestas por Haber (1999: 310-311): las ciencias sociales históricas, la historia tradicional, y la nueva historia cultural. Como las ciencias sociales históricas, la nueva filología "enfatiza la consistencia lógica” (en el uso del lenguaje y en su significado cultural), "enmarca hipótesis" tomadas de un género documental y las pone a prueba utilizando otro género (por ejemplo, la evidencia de conflictos políticos y los registros de los resultados de elecciones locales), y analiza "datos recolectados de manera sistemática” ( $v . g$. análisis de préstamos lingüísticos, tabulación de bienes mencionados en testamentos indígenas). Al igual que la historia tradicional, la nueva filología tiende a construir "narraciones autoritarias" mediante 
"testimonios de primera mano, en un sentido legal" corroborados por "relatos similares" con la ayuda del "razonamiento por analogía" y una cierta participación de la "imaginación histórica" (todo lo cual es de gran relevancia para la lectura de los documentos cotidianos notariales que son el pan de cada día de la nueva filología). De manera similar a la nueva historia cultural, la nueva filología se ha interesado por el estudio de "grupos subordinados" (v.g. indígenas mesoamericanos, particularmente mujeres) y se ocupa del "estudio de las mentalidades" y sus "sistemas simbólicos" (Van Young, 1999: 218), como se comprueba en el estudio neofilológico de la conquista espiritual y las prácticas religiosas mesoamericanas en el período colonial. Con respecto a otras características de la nueva historia cultural propuestas por Van Young, me parece que la nueva filología es deductivista más bien que inductivista, y es cautelosa y sensitiva en su acercamiento a las fuentes, mas no "sumamente crítica" de las mismas.

Es posible que esta caracterización de la nueva filología norteamericana como una corriente de gran influencia en otras disciplinas donde confluyen los mejores aspectos historiográficos parezca ser arrogante, egoísta, y aun un tanto imperialista, ya que este ensayo está volcado de manera exclusiva al ámbito académico norteamericano. Después de todo, hay muchas labores de investigación que la nueva filología no ha emprendido, y algunas labores que han sido pobremente realizadas. Van Young (1999: 24) expresa una crítica muy válida al afirmar que esta escuela se inclina hacia "el sentimiento de que la investigación ha concluido cuando la filología ha concluido". Sin embargo, al haber llegado al final de este ensayo, quisiera presentar una aseveración retórica, más bien que una crítica substancial de la nueva filología. En este nuevo siglo, la importancia de la nueva filología reside en su creciente erosión de una identidad singular, y en la persistencia de su influencia e incorporación en los campos de la historia colonial en Mesoamérica (y tal vez en otras regiones de América Latina). Metafóricamente hablando, puede decirse que todo investigador de la etnohistoria colonial mexicana podría convertirse en un practicante de la nueva filología. La prueba más contundente del valor de la nueva filología podría ser su eventual invisibilidad.

\section{Lista bibliográfica de la nueva filología}

Esta lista incluye todas las monografías en lengua inglesa mencionadas en este artículo que fueron publicadas desde 1976 hasta el presente; se excluyen algunos artículos, y se mencionan los títulos de disertaciones doctorales solamente si éstas siguen siendo inéditas.

Anderson, Arthur y Charles E. Dibble, 1955-1982, The Florentine Codex, 12 vols, University of Utah Press, Salt Lake City.

Anderson, Arthur, Frances Berdan y James Lockhart, 1976, Beyond the Codices, University of California Press, Berkeley.

Anderson, Arthur y Susan Schroeder (eds), 1997, Codex Chimalpahin, vols. 1 y 2, University of Oklahoma Press, Norman.

Andrews, J. Richard y Ross Hassig, 1984, Treatise on the Heathen Superstitions That Today Live Among the Indians Native to This New Spain, by Hernando Ruiz de Alarcón, University of Oklahoma Press, Norman.

Bierhorst, John, 1985, Cantares Mexicanos: Songs of the Aztecs; y A Nahuatl-English Dictionary and Concordance to the Cantares Mexicanos, 2 vols., Stanford University Press, Stanford.

— 1992, History and Mythology of the Aztecs: The Codex Chimalpopoca; y Codex Chimalpopoca: The Text in $\mathrm{Na}$ huatl with a Glossary and Grammatical Notes, University of Arizona Press, Tucson.

Bricker, Victoria, 1981, The Indian Christ, the Indian King: The Historical Substrate of Maya Myth and Ritual, University of Texas Press, Austin.

Burkhart, Louise, 1989, The Slippery Earth: Nahua-Christian Moral Dialogue in Sixteenth-Century Mexico, University of Arizona Press, Tucson.

__ 1995, "The Voyage of Saint Amaro: A Spanish Legend in Nahuatl Literature", en Colonial Latin American Review, 4, pp. 29-57.

_- 1996a, Holy Wednesday: A Nahua Drama from Early Colonial Mexico, University of Pennsylvania Press, Filadelfia.

— 1996b, "Indigenous Literature in Preconquest and Colonial Mesoamerica", en The Legacy of Mesoamerica: History and Culture of a Native American Civilization, Robert Carmack, Janine Gasco, y Gary Gossen (eds.), Prentice Hall, Upper Saddle River, NJ, pp. 407-41.

Cline, S.L., 1986, Colonial Culhuacan, 1580-1600: A Social History of an Aztec Town, University of New Mexico Press, Albuquerque. 
(ed.), 1993, The Book of Tributes: Early-Sixteenth-Century Nahuatl Censuses from Morelos, UCLA Latin American Center Publications, Los Ángeles.

- y Miguel León-Portilla (eds.), 1984, The Testaments of Culhuacan, UCLA Latin American Center, Los Ángeles.

Edmonson, Munro S., 1982, The Ancient Future of the Itza: The Book of Chilam Balam of Tizimin, University of Texas Press, Austin.

__, 1986, Heaven Born Merida and Its Destiny: The Book of Chilam Balam of Chumayel, University of Texas Press, Austin.

Gibson, Charles, 1964, The Aztecs under Spanish rule: A History of the Indians of the Valley of Mexico, 1519-1810, Stanford University Press, Stanford.

Gruzinksi, Serge, 1993, The Conquest of Mexico: The Incorporation of Indian Societies into the Western World, 16th18th Centuries, Polity Press, Cambridge, Inglaterra.

Hanks, William F., 1986, "Authenticity and Ambivalence in the Text: A Colonial Maya Case”, en American Ethnologist, 13: 4, pp. 721-744.

_ 1987 , "Discourse Genres in a Theory of Practice", en American Ethnologist, 14: 4, pp. 668-692.

__, 1996, Language and Communicative Practices, Westview Press, Boulder.

Haskett, Robert S., 1991, Indigenous Rulers: An Ethnohistory of Town Government in Colonial Cuernavaca, University of New Mexico Press, Albuquerque.

Hill, Robert M., II, 1992, Colonial Cakchiquels: Highland Maya Adaptation to Spanish Rule, 1600-1700, Harcourt Brace, Fort Worth.

Horn, Rebecca, 1997, Postconquest Coyoacan: Nahua-Spanish Relations in Central Mexico, 1519-1650, Stanford University Press, Stanford.

Karttunen, Frances, 1982, "Nahuatl Literacy”, en The Inca and Aztec States, 1400-180o, George Collier et al. (eds. ), Academic Press, Nueva York, pp. 395-417.

— 1983, An Analytical Dictionary of Nahuatl, University of Texas Press, Austin.

- 1985, Nahuatl and Maya in Contact with Spanish, Texas Linguistic Forum, 26, University of Texas, Department of Linguistics, Austin.

— y James Lockhart, 1976, Nahuatl in the Middle Years: Language Contact Phenomena in Texts of the Colonial Period, University of California Publications in Linguistics, 85, University of California Press, Berkeley y Los Ángeles.

- 1987, The Art of Nahuatl Speech: The Bancroft Dialogues, UCLA Latin American Center Publications, Los Ángeles.

Kellogg, Susan M., 1995, Law and the Transformation of Aztec Culture, 1500-1700, University of Oklahoma Press, Norman.
_ genous Testaments of Colonial Mesoamerica and the Andes, University of Utah Press, Salt Lake City.

Leibsohn, Dana, 1993, The Historia Tolteca-Chichimeca: Recollecting Identity in a Nahua Manuscript, PhD dissertation, University of California, Los Ángeles.

Lockhart, James., 1991a, Nahuas and Spaniards. Postconquest Central Mexican History and Philology, Stanford University Press y UCLA Latin American Center Publications, Stanford y Los Ángeles.

—, 1992, The Nahuas After the Conquest: A Social and Cultural History of the Indians of Central Mexico, Sixteenth Through Eighteenth Centuries, Stanford University Press, Stanford.

- 1993, We People Here: Nahuatl Accounts of the Conquest of Mexico, University of California Press, Berkeley y Los Ángeles.

— 2000, Of Things of the Indies: Essays Old and New in Early Latin American History, Stanford University Press, Stanford.

Lockhart, James, Frances Berdan y Arthur Anderson, 1986, The Tlaxcalan Actas: A Compendium of the Records of the Cabildo of Tlaxcala (1545-1627), University of Utah Press, Salt Lake City.

Mannheim, Bruce, 1991, The Language of the Inka Since the European Invasion, University of Texas Press, Austin.

Maxwell, Judith M. y Craig A. Hanson, 1993, Of the Manners of Speaking That the Old Ones Had: The Metaphors of Andrés de Olmos in the Tulal Manuscript, University of Utah Press, Salt Lake City.

Offutt, Leslie, 1992, "Levels of Acculturation as Suggested by San Esteban Testaments: A Comparison of Wills from the Sevententh and Eighteenth Centuries", en Estudios de Cultura Náhuatl, 22, pp. 409-443.

Restall, Matthew, 1995a, Life and Death in a Maya Community: The Ixil Testaments of the 1760s, Labyrinthos, Lancaster, California.

— 1995 b, “'He wished it in vain': Subordination and Resistance Among Maya Women in Colonial Yucatan”, en Ethnohistory, 42: 4 , otoño, pp. 577-594.

__ 1995c, “'The Document Shall Be Seen': Yucatec Maya Literacy”, en Chipping Away on Earth: Studies in Prehispanic and Colonial Mexico in Honor of Arthur J.O. Anderson and Charles E. Dibble, Eloise Quiñones Keber (ed.), Labyrinthos, Lancaster, CA, pp. 119-130.

- 1997a, The Maya World: Yucatec Culture and Society, 1550-1850, Stanford University Press, Stanford.

— 1997b, "Heirs to the Hieroglyphs: Indigenous Literacy in Colonial Mesoamerica", en The Americas, 54: 2, pp. 239-267.

__, 1998, Maya Conquistador, Beacon Press, Boston. 
Salomon, Frank y George L. Urioste, 1991, The Huarochiri Manuscript: A Testament of Ancient and Colonial Andean Religion, University of Texas Press, Austin.

Schroeder, Susan, 1991, Chimalpahin and the Kingdoms of Chalco, University of Arizona Press, Tucson.

— 2000, "Jesuits, Nahuas, and the Good Death Society in Mexico City, 1710-1767", en Hispanic American Historical Review, 80: 1, pp. 43-76.

Schroeder, Susan, Stephanie Wood y Robert Haskett (eds.), 1997, Indian Women of Early Mexico, University of Oklahoma Press, Norman.

Sell, Barry D., 1994, Friars, Nahuas, and Books: Language and Expression in Colonial Nahuatl Publications, PhD dissertation, University of California, Los Ángeles.

Sigal, Pete, 2000, From Moon Goddesses to Virgins: The Colonization of Yucatecan Maya Sexual Desire, University of Texas Press, Austin.

Sousa, Lisa (ed.), 1992, Indigenous Writing in the Spanish Indies, UCLA Historical Journal Special Issue, vol. 12, Los Ángeles.

Sousa, Lisa, 1998, Women in Native Societies and Cultures of Colonial Mexico, PhD dissertation, University of California, Los Ángeles.

Sousa, Lisa, Stafford Poole y James Lockhart, 1998, The Story of Guadalupe: Luis Laso de la Vegaís Huei tlamahuiçoltica of 1649, Stanford University Press y UCLA Latin American Center Publications, Stanford y Los Ángeles.

Tedlock, Dennis, 1985, Popol Vuh: The Definitive Edition of the Mayan Book of the Dawn of Life, Simon and Schuster, Nueva York.

Terraciano, Kevin, 1994, Nudzahui History: Mixtec Writing and Culture in Colonial Oaxaca, PhD dissertation, University of California, Los Ángeles.

__ 2000, "The Colonial Mixtec Community", en Hispanic American Historical Review, 80: 1, pp. 1-42.

Thompson, Philip C., 1978, Tekanto in the Eighteenth Century, $\mathrm{PhD}$ dissertation, Tulane University.

Wood, Stephanie, 1984, Corporate Adjustments in Colonial Mexican Indian Towns: Toluca Region, PhD dissertation, University of California, Los Ángeles.

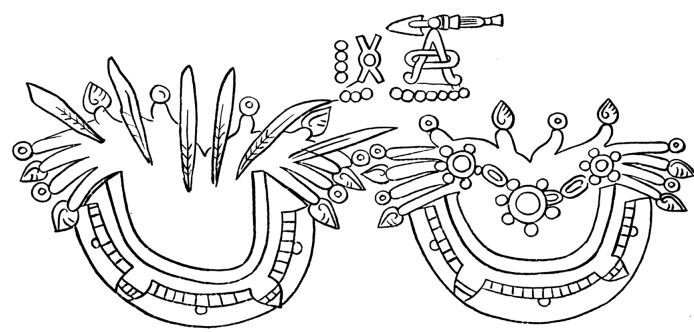

Códice Selden

\section{LISTA DE ENSAYOS HISTORIOGRÁFICOS}

Esta lista menciona los ensayos arriba citados. Véase asimismo los ensayos bibliográficos publicados por Sarah Cline sobre los nahuas, por Grant D. Jones sobre los mayas de Yucatán y por W. George Lovell sobre los mayas guatemaltecos, en The Cambridge History of the Native Peoples of the Americas, vol. II, Mesoamerica, parte 2, Cambridge University Press, Cambridge, 2000.

Edmonson, Munro y Victoria R. Bricker, 1985, "Yucatecan Mayan Literature", en Supplement to the Handbook of Middle American Indians, vol. 3, Literatures, Munro Edmonson y Victoria R. Bricker (eds.), University of Texas Press, Austin, pp. 44-63.

Haber, Stephen, 1999, “Anything Goes: Mexico's 'New' Cultural History", en Hispanic American Historical Review, 79: 2, mayo, pp. 309-330.

Kicza, John E., 1995, "Recent Books on Ethnohistory and Ethnic Relations in Colonial Mexico", en Latin American Research Review, 30: 3, pp. 239-253.

Latin American Subaltern Studies Group, 1995, "Founding Statement", en The Postmodernism Debate in Latin America, John Beverly, Michael Aronna y José Oviedo (eds.), Duke University Press, Durham.

Lockhart, James, 1972, "The Social History of Colonial Spanish America: Evolution and Potential”, en Latin American Research Review, 7: 1, pp. 6-45 [reeditado en Lockhart, 2000: 27-80.]

__ 1991b, "A Vein of Ethnohistory", en Nahuas and Spaniards. Postconquest Central Mexican History and Philo$\log y$, Stanford University Press y UCLA Latin American Center Publications, Stanford y Los Ángeles, pp. 182-200.

Lomnitz, Claudio, 1999, "Barbarians at the Gate?: A Few Remarks on the Politics of the "New Cultural History of Mexico'", en Hispanic American Historical Review, 79: 2, mayo, pp. 367-383.

Mallon, Florencia E., 1994, "The Promise and Dilemma of Subaltern Studies: Perspectives from Latin American History", en American Historical Review, 99: 5, pp. 1491-1515.

Radding, Cynthia, 1998, "Cultural Dialogues: Recent Trends in Mesoamerican Ethnohistory”, en Latin American Research Review, 33: 1, pp. 193-211.

Socolow, Susan, 1999, "Putting the 'Cult' in Culture", en Hispanic American Historical Review, 79: 2, mayo, pp. 355-365. Spalding, Karen, 1972, “The Colonial Indian: Past and Future Research Perspectives”, en Latin American Research Review, 7: 1, pp. 47-76.

Van Young, Eric, 1999, “The New Cultural History Comes to Old Mexico", en Hispanic American Historical Review, 79: 2, mayo, pp. 211-247. 